\title{
Addressing Longevity, Life Expectancy and Health Life Expectancy
}

\author{
Sarah Harper ${ }^{1}$
}

Published online: 6 November 2015

(C) Springer Science+Business Media Dordrecht 2015

When JPA first tackled the question of longevity back in 2008, (Harper and Howse 2008) we raised four key questions which we believed frame the current debate:

1. Will increases in both life expectancy and in life extension or longevity continue that is will there be an increase in average years lived by humans and also maximum years attained by a human being?

2. Will life expectancy increase in line with life extension - that is will we all enjoy the benefits of longevity or will it only be for a few?

3. Will increases in life expectancy be accompanied by increases in life extension or are we seeing a compression of longevity after 100 - that is will the predicted increases in centenarians over the coming century be accompanied by increases in super-centenarians?

4. And will advances in life expectancy be matched by advances in healthy life expectancy?

We still believe these to be important and unresolved.

In 2009, we considered the evidence that mortality reductions in the oldest-old, over 80 years, showed no sign of slowing down. Indeed, data from Japan, which has the lowest mortality in the world, still shows no sign of a compression of mortality, and thus no indication that we are approaching an upper limit to human longevity in the developed world. This is contrary to the expectations of some analysts in the 1980s, and as a result the modal age at death continues to shift upwards. We highlighted work by Cheung and Robine (2007), who analysed Japanese mortality from 1950 to 2000. This showed that not only had there been a strong and linear increase in the modal age at death over the previous 50 years, but also the standard deviation of ages at death above the mode had stopped decreasing in the mid-1980s for women and in the 1990s for

Sarah Harper

sarah.harper@ageing.ox.ac.uk

1 Oxford Institute of Population Ageing, University of Oxford, Oxford, UK 
men. In other words, data from the country with the lowest mortality in the world showed no sign of a compression of mortality.

We were keen to encourage publication of methodological advances in this area, for example like those of Robine and Paccaud (2005), who suggested measures based on the number of centenarians in the population; both the 'centenarian doubling time'the number of years needed to double the number of people aged 100 years + in a population; and the 'centenarian rate' - the number of survivors aged 100 years from a given birth cohort at a given date divided by the size of the cohort at some given age.

We also suggested that we needed to move from considering the potential effect of eliminating certain major causes of death altogether to estimating the impact on life expectancy of delaying the onset of what we know to be age-related diseases.

Our review concluded that 21 st Century mortality would most likely still be shaped by healthy living, disease prevention and cure, but that regenerative medicine and ageretardation would play an increasingly larger part. This is still an area where much research is needed.

Our second discussion point was around health expectancies. In terms of the relationship of life expectancy to healthy life expectancy, there are three main theoretical stances:

1. Compression of morbidity, where healthy life expectancy (HLE) increases faster than life expectancy (LE) and extra years of life are healthy ones.

2. Expansion of morbidity, where HLE does not keep pace with LE, the extra years of life are unhealthy ones, so that the modern drivers of longevity (science and technology) are enabling those with frailty to live longer.

3. And the concept of dynamic equilibrium, where disabled life expectancy (DLE) is increasing but the severity of ill health is reducing. A general conclusion is that we are pushing back the onset of frailty but maintaining that state for longer.

Since then, evidence has suggested that increases in healthy life expectancies, or an expansion of health and disability, are not keeping pace with gains in life expectancy in several EU countries, and in Japan and the US, particularly at older ages. Other European countries, such as Belgium and Sweden, however, appear to be experiencing compression of disability, possibly due to smaller gains in life expectancy. Furthermore, since our review there have been several good studies using cross-sectional data (Hashimoto et al. 2012; Klijs et al. 2011a, 2011b), and longitudinal studies (Locke et al. 2013; Wu et al. 2015; Jagger et al. 2015). These have started to consider both chronic conditions and health behaviours, by, for example, researching the important question of the role of obesity on DFLE (Disability Free Life Expectancy) and LE. The conclusion seems to be that obesity has more of an impact on DFLE than on LE, with obesity reducing LE at age 55 by only 1.4 years but increasing years with disability by 5.9 years (Klijs et al. 2011a). Of equal importance is the recent analysis of international studies of dementia (Wu et al. 2015), which reveals a decrease in the prevalence of dementia in some countries. Furthermore, the authors argue that their evidence from Western European studies reinforces the potential of preventive strategies throughout life to reduce dementia risk rather than the overemphasis on pharmaceutical interventions. 
A major limitation, however, to our ability to undertake such comparisons remains the lack of comparable measures of HLE although the Global Burden of Disease programme does estimate healthy life expectancy for 187 countries worldwide, thus providing comparative data (Salomon et al. 2012). Similarly, the introduction in the European Union of healthy life years (HLY), a Disability Free Life Expectancy measure, has allowed comparative work among EU countries, and the Global Activity Limitation Indicator (GALI), while having limitations, attempts to measure restrictions in participating in social and economic roles, and is thus in line with "participation restriction" as envisaged in the World Health Organization International Classification of Functioning, Disability and Health (Berger et al. 2015).

In terms of inequalities in both LE and HLE, we pointed out it was originally thought that social class differentials in mortality were to be understood mainly in terms of poverty measures. More recently, the focus has been on the social gradient in mortality risk, whereby lower income groups within a society have a higher mortality rate, despite being well above the poverty line. Socio-economic status (SES) rather than poverty has now become the central concept for investigating social inequalities in both mortality and in ill health/disability (Jagger and Robine 2011).

Since our first review, our understanding of health inequalities has improved through the detailed analysis of SHARE data, for example, (Jagger 2011); of the European Union Statistics on Income and Living Conditions (EU-SILC) survey (Fouweather et al. 2015), which suggest that inequalities in HLY at age 50 across Europe are large, increasing and partly explained by levels of material deprivation, and that long-term unemployment has become more influential in explaining variation in HLY at 50; or specific national data sets (Howse et al. 2011) which stressed the need to explore inequalities at the local level.

There has been clear progress in our understanding of these questions, and some improvement in the availability of cross comparative data. Understanding these questions is essential to preparing for the continued ageing of global populations, and to understanding how the challenges, which lie ahead, need to be framed.

It is an area of research to which the JPA will continue to return.

\section{References}

Berger, N., Van Oyen, H., Cambois, E., Fouweather, T., Jagger, C., Nusselder, W., \& Robine, J.-M. (2015). Assessing the validity of the global activity limitation indicator in fourteen European countries. $B M C$ Medical Research Methodology, 15, 1.

Cheung, S. L. K., \& Robine, J. (2007). Increase in common longevity and the compression of mortality: the case of Japan. Population Studies, 61(1), 85-98.

Fouweather, T., Gillies, C., Wohland, P., Van Oyen, H., Nusselder, W., Robine, J. M., Cambois, E. \& Jagger, C. (2015). Comparison of socio-economic indicators explaining inequalities in Healthy Life Years at age 50 in Europe: 2005 and 2010. The European Journal of Public Health, 1-6.

Harper, S., \& Howse, K. (2008). An upper limit to longevity? Population Ageing, 1, 99-106. doi:10.1007/ s12062-009-9013-5.

Hashimoto, S., Kawado, M., Yamada, H., Seko, R., Murakami, Y., Hayashi, M., Kato, M., Noda, T., Ojima, T., Nagai, M. \& Tsuji, I. (2012). Gains in disability-free life expectancy from elimination of diseases and injuries in Japan. Journal of Epidemiology 22, 199-204.

Howse, K., et al. (2011). Socio-geographic variations in mortality in a large retired UK population. Population Ageing, 4, 231-249. doi:10.1007/s12062-011-9054-4. 
Jagger. (2011). Inequalities in health expectancies at older ages in the european union: findings from the survey of health and retirement in Europe (SHARE). Journal of Epidemiology and Community Health. doi:10.1136/jech.2010.117705.

Jagger, C., \& Robine, J. M. (2011). Healthy life expectancy. In R. G. Rogers \& E. M. Crimmins (Eds.), International handbook of adult mortality (pp. 551-568). Netherlands: Springer.

Jagger, C., Matthews, F., Wohland, P., Fouweather, T., Stephan, B., Robinson, L., Arthur, A. and Brayne, C. (2015). A comparison of health expectancies from the cognitive function and ageing studies over two decades in England. Lancet (in press).

Klijs, B., Mackenbach, J. P., \& Kunst, A. E. (2011a). Obesity, smoking, alcohol consumption and years lived with disability: a Sullivan life table approach. BMC Public Health, 11, 378.

Klijs, B., Nusselder, W. J., Looman, C. W., \& Mackenbach, J. P. (2011b). Contribution of chronic disease to the burden of disability. PloS One, 6, e25325.

Locke, E., Thielke, S., Diehr, P., Wilsdon, A. G., Barr, R. G., Hansel, N., Kapur, V. K., Krishnan, J., Enright, P., Heckbert, S. R., Kronmal, R. A., \& Fan, V. S. (2013). Effects of respiratory and non-respiratory factors on disability among older adults with airway obstruction: the cardiovascular health study. Journal of Chronic Obstructive Pulmonary Disease, 10, 588-596.

Salomon, J. A., Wang, H., Freeman, M. K., Vos, T., Flaxman, A. D., Lopez, A. D., \& Murray, C. J. L. (2012). Healthy life expectancy for 187 countries, 1990-2010: a systematic analysis for the global burden disease study 2010. Lancet, 380, 2144-2162.

Yu-Tzu, W., Fratiglioni, L., Matthews, F. E., Lobo, A., Breteler, M. M. B., Skoog, I., Brayne, C. (2015). Dementia in Western Europe: epidemiological evidence and implications for policy making, www. thelancet.com/neurology Published online August 21, 2015. 